\title{
Proper Hand Washing for Elders
}

Hand washing is an important way to reduce the spread of infectious diseases. Germs from human and animal sources can be transmitted to hands, which can transmit the germs to other people, foods, and anything else that the hands touch. Proper hand washing can reduce the numbers of harmful microorganisms on our hands and reduce the risk of some diseases.

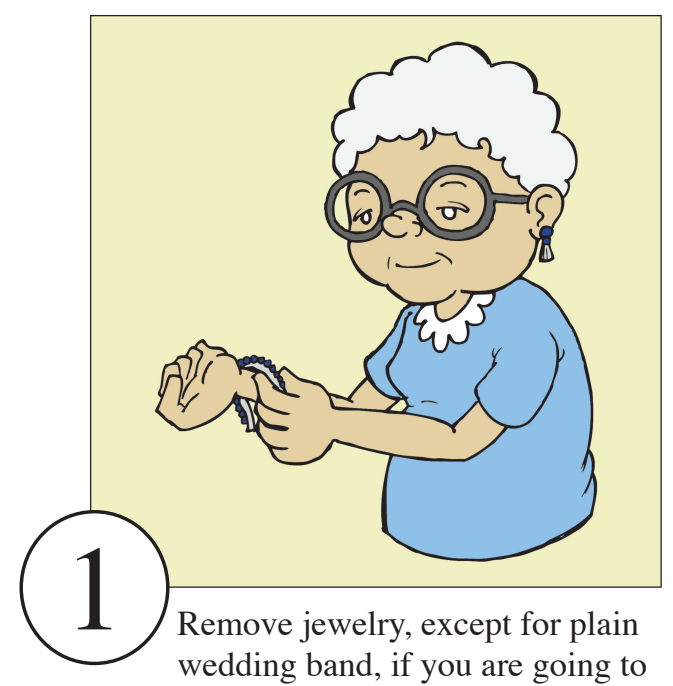
prepare foods.

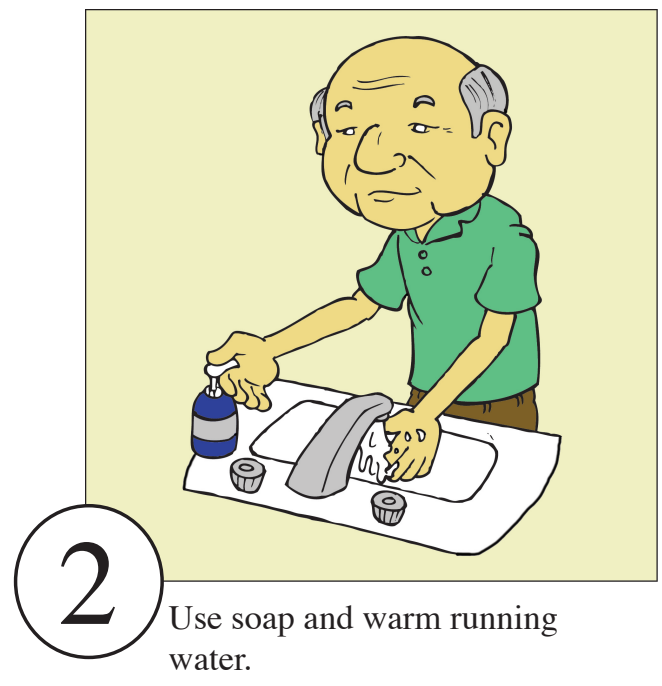

water.

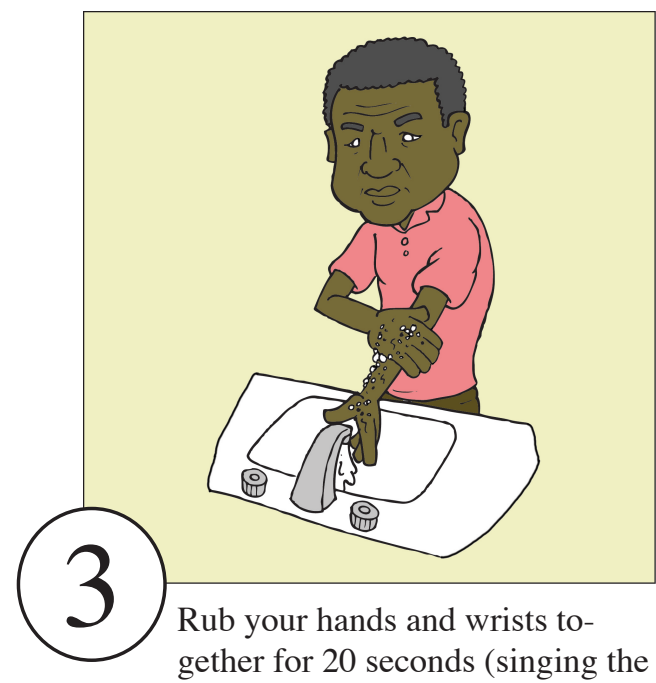

Happy Birthday song twice). Use soap up to your elbows if they are dirty.
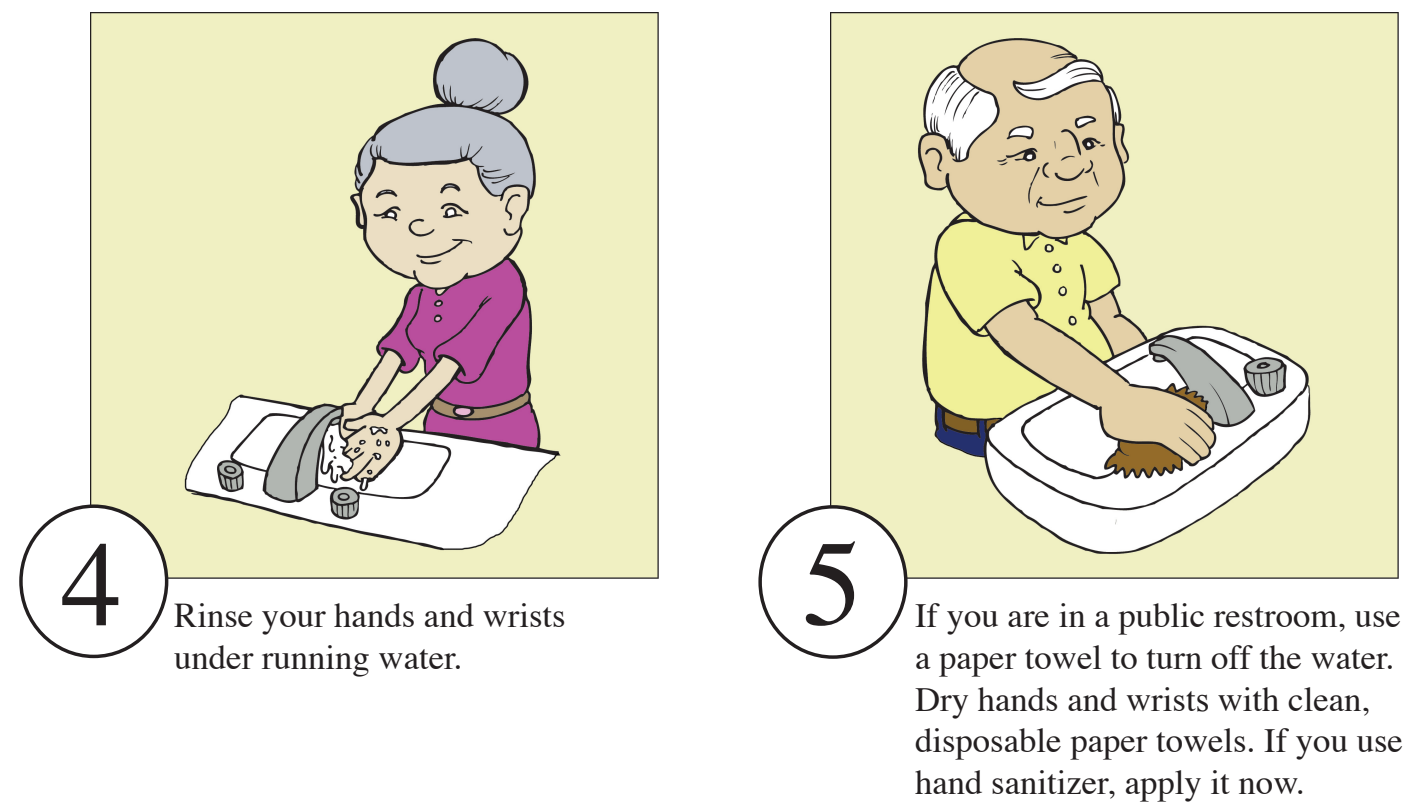

\section{Wash your hands before:}

- Eating or drinking

- Handling or preparing foods

- Touching serving utensils

- Serving foods

\section{Wash your hands after:}

- Visiting the restroom

- Covering your nose or mouth when you cough or sneeze

- Gardening or working outdoors

- Handling pets and their waste

- Working with raw foods

- Changing baby diapers

- Doing other activities that dirty your hands 